\title{
Evidence that the seasonally breeding Bennett's wallaby (Macropus rufogriseus rufogriseus) does not exhibit short-day photorefractoriness
}

\author{
A. S. I. Loudon and J. D. Curlewis* \\ M.R.C./A.F.R.C. Comparative Physiology Research Group, Institute of Zoology, Regent's Park, \\ London NWI 4RY, UK
}

\begin{abstract}
Summary. Adult female Bennett's wallabies $(N=6)$ were maintained in artificial winter solstitial daylengths commencing 3 weeks before the winter solstice for 16 or 42 weeks. Such treatment effectively prevented the normal establishment of seasonal reproductive quiescence with animals continuing to exhibit reproductive cycles beyond the time of the normal termination of the breeding season. Animals maintained in natural photoperiods or simulated natural changes in daylength after the winter solstice all entered reproductive quiescence by early February. In the Bennett's wallaby, therefore, the breeding season does not terminate as a result of refractoriness to short daylengths. Our results indicate that the relatively small increases in photoperiod shortly after the winter solstice provide the environmental signal responsible for initiating the onset of seasonal reproductive quiescence which normally occurs $5-8$ weeks after the solstice. These results contrast with the effect of fixed artificial summer solstitial daylengths on the onset of the breeding season in which breeding begins spontaneously at the normal time of year as a result of long-day photorefractoriness.
\end{abstract}

Keywords: Bennett's wallaby; photoperiod; refractoriness; seasonality

\section{Introduction}

The mechanisms responsible for the initiation and termination of the breeding season in seasonally breeding mammals are poorly understood. There is a general recognition that photorefractoriness to both inhibitory and stimulatory photoperiods plays a central role in timing the breeding season (see Nicholls et al., 1988, for review). In a large number of seasonally breeding mammals refractoriness to short photoperiods, rather than a direct response to increasing daylengths may be the primary factor responsible for inducing gonadal regression or reactivation in early spring. Thus, in sheep maintained in fixed winter solstitial photoperiods, the breeding season terminates irrespective of an increase in daylength or decrease in the duration of secretion of the pineal hormone melatonin (Robinson \& Karsch, 1984). In the European rabbit and 4 species of hamster gonadal reactivation spontaneously occurs in animals maintained in short photoperiods (European rabbit: Boyd, 1985; golden/Syrian hamster: Turek et al., 1975; Siberian/Djungarian hamster: Hoffmann, 1973; Turkish hamster: Carter et al., 1982; European hamster: Canguilhem et al., 1986). The phenomenon of refractoriness to previously inductive or inhibitory photoperiods observed in many species of mammal demonstrates that the neuroendocrine axis is not simply a passive transducer of photoperiodic information driven by seasonal changes in daylength.

\footnotetext{
*Present address: Department of Physiology and Pharmacology, University of Queensland, St Lucia, Queensland 4067, Australia.
} 
In seasonally breeding wallabies, reproduction is known to be under the control of photoperiod (reviewed by Tyndale-Biscoe et al., 1986). As in eutherians, seasonality in wallabies is controlled via a pineal-dependent mechanism involving the pattern of secretion of pineal melatonin (tammar wallaby: McConnell \& Tyndale-Biscoe, 1985; McConnell \& Hinds, 1985; McConnell et al., 1986; Bennett's wallaby: Loudon et al., 1985; Loudon \& Curlewis, 1987; Curlewis \& Loudon, 1988a). Seasonally breeding wallabies also clearly exhibit the phenomenon of photorefractoriness with respect to long photoperiods. Adult females kept in fixed long photoperiods spontaneously commence breeding without the need to experience a decline in daylength (tammar wallaby: Sadleir \& Tyndale-Biscoe, 1977; Bennett's wallaby: Curlewis \& Loudon, 1989; B. R. Brinklow \& A. S. I. Loudon unpublished observations).

In the seasonally breeding Bennett's (Macropus rufogriseus rufogriseus) and tammar (Macropus eugenii) wallabies the breeding season begins with the termination of embryonic diapause several weeks after the summer solstice (tammar: Flint \& Renfree, 1982; Hinds \& den Ottolander, 1983; Bennett's: Merchant \& Calaby, 1981; Curlewis et al., 1986). There is a post-partum oestrus at which the majority of females mate and conceive. The resulting conceptus develops to a unilaminar 80-100-cell blastocyst whereupon both the blastocyst and the corpus luteum (CL) enter a period of quiescence which in most animals is maintained until the following breeding season (TyndaleBiscoe et al., 1974; Merchant \& Calaby, 1981; Curlewis et al., 1987). During the breeding season the sucking activity by the pouch young inhibits reactivation of the CL (Renfree, 1979); the removal or loss of the pouch young results in the reactivation of the $\mathrm{CL}$, an increase in secretion of progesterone and the subsequent reactivation of the embryo, with birth following 27 days later (Merchant, 1979; Merchant \& Calaby, 1981; Hinds \& Tyndale-Biscoe, 1982; Curlewis et al., 1987).

From a time soon after the winter solstice to shortly after the summer solstice, the corpus luteum and embryo remain in a state of quiescence regardless of whether a pouch young is present (Merchant \& Calaby, 1981). This is termed seasonal quiescence. The precise timing of the termination of the breeding season has not been defined in the tammar wallaby but occurs 6-8 weeks after the winter solstice in the Bennett's wallaby (Curlewis et al., 1987; Loudon \& Curlewis 1987). Here, we present the results of experiments designed to examine whether the termination of the breeding season, and thus the onset of seasonal quiescence, in the Bennett's wallaby can occur as a result of refractoriness to short photoperiods.

\section{Materials and Methods}

Animals. Mature female wallabies were obtained from the free-ranging population at Whipsnade Park, Bedfordshire, and maintained in outside pens under natural photoperiod and temperature (London, $51^{\circ} 30^{\prime} \mathrm{N}$ ) in the presence of a male whose underbelly was covered with coloured grease as previously described (Curlewis et al., 1987). Such colourmarked males leave a conspicuous mark on the rump of females at the time of mating and such marks are easier to detect than the plugs which result from fertile matings. During exposure to experimental photoperiods, animals were restricted to the indoor part of the accommodation under artificial illumination from 16:00 to 08:00 $\mathrm{h}$ and allowed access to the outside from 08:00 to 16:00 h. Details of these pens and the level of artificial illumination are contained in Loudon \& Curlewis (1987). The duration of artificial photoperiod was determined from Royal Observatory Tables, Greenwich and civil twilight was added to the duration of daylength as previously described (Loudon \& Curlewis, 1987).

Experiment 1 . Six aduit females with pouch young were exposed to artificial winter solstice daylengths from 2

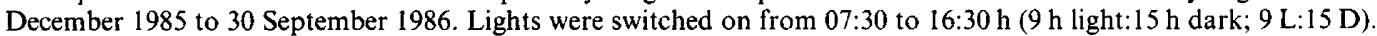
On 5 February 1986, all pouch young were removed. Subsequent pouch young were removed within 7 days of birth throughout the course of the experiment. A second group of 9 females was maintained under conditions of natural photoperiod and temperature from early December to the end of May. In this group, pouch young were removed on 20 December and, if present, on 5 February and 6 March. Throughout the experiment, blood samples were collected twice weekly for the determination of progesterone concentration, pouches were checked regularly for the presence of a neonate and the females' rumps checked for the presence of a mating mark from the colour-marked male. Data from the latter group of 9 females have already been reported by Curlewis et al. (1987; Exp. 3).

Experiment 2. Three groups of females with pouch young were exposed either to natural photoperiods (Group 2a, 7 females), a simulated natural photoperiod (Group 2b, 6 females), or fixed winter solstitial photoperiod (Group 2c, 
6 females) from 5 December 1986 to 30 March 1987. Group 2a was maintained in outdoor pens throughout the experimental period and was therefore exposed to natural changes in photoperiod and temperature. Group $2 \mathrm{c}$ was maintained in 9 L:15 D under identical lighting and husbandry conditions as described for Exp. 1 above. Group $2 b$ animals were exposed to winter solstice daylengths from 5 December to 30 December and then to a regimen of weekly increases in photoperiod designed to mimic changes in natural daylength at that time of year. For the 13-week period from 3I December to 25 March daylength was increased by $6,10,17,20,21,24,25,27,27,28,28$, and 28 min per week by an equal extension of dawn and dusk. Apart from differences in experimental photoperiod, Groups $2 b$ and $2 c$ were maintained under identical husbandry conditions and exposed to similar daily changes in temperature. On 13 January 1987 all pouch young were removed and any subsequent pouch young were removed within a week of birth. All females were blood sampled twice weekly between 09:00 and 11:00 h and inspected at least twice weekly for the presence of newborn young. On 22 January one animal in Group 2a died and was replaced. Males were not present with any of the experimental groups.

Blood sampling and progesterone assay. Blood was collected by venepuncture of the lateral tail vein and kept on ice until centrifugation. Plasma was separated and stored at $-20^{\circ} \mathrm{C}$ until assayed. Plasma was extracted with $n$-hexane and progesterone concentration measured by radioimmunoassay as previously described (Curlewis et al., 1987). The limit of detection of the assay was $20 \mathrm{pg} / \mathrm{ml}$ plasma and the inter- and intra-assay coefficients of variation were $14 \cdot 2$ and $5.8 \%$ respectively. Progesterone values of $<300 \mathrm{pg} / \mathrm{ml}$ in animals of this species are considered to be indicative of a quiescent CL (Curlewis et al., 1987).

\section{Results}

In Exp. 1, 7 out of 9 animals maintained under natural photoperiod underwent no further reproductive cycles following removal of pouch young in February; the remaining 2 females gave birth in early March but underwent no further cycles following pouch young removal (Curlewis et al., 1987). All animals maintained in short $(9 \mathrm{~L}: 15 \mathrm{D})$ photoperiods continued to undergo reproductive

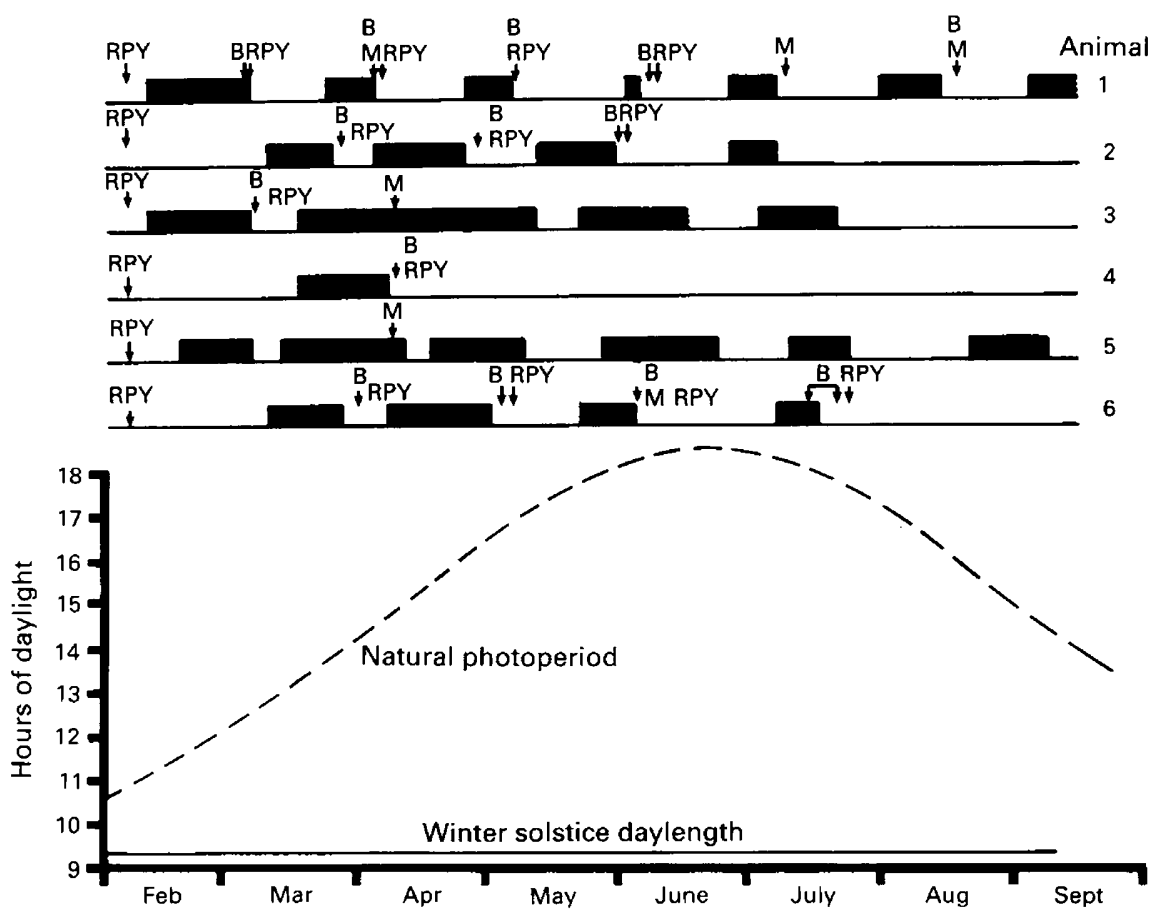

Fig. 1. Reproductive activity of 6 female Bennett's wallabies maintained in fixed winter solstitial photoperiods from 2 December to 30 September. Solid bars indicate periods when plasma progesterone samples (based on twice weekly blood samples) were $>300 \mathrm{pg} / \mathrm{ml}$. All pouch young were removed on 5 February (RPY) and subsequent young born were removed as indicated. Births (B) and mating marks from colour-marked males (M) are indicated. 


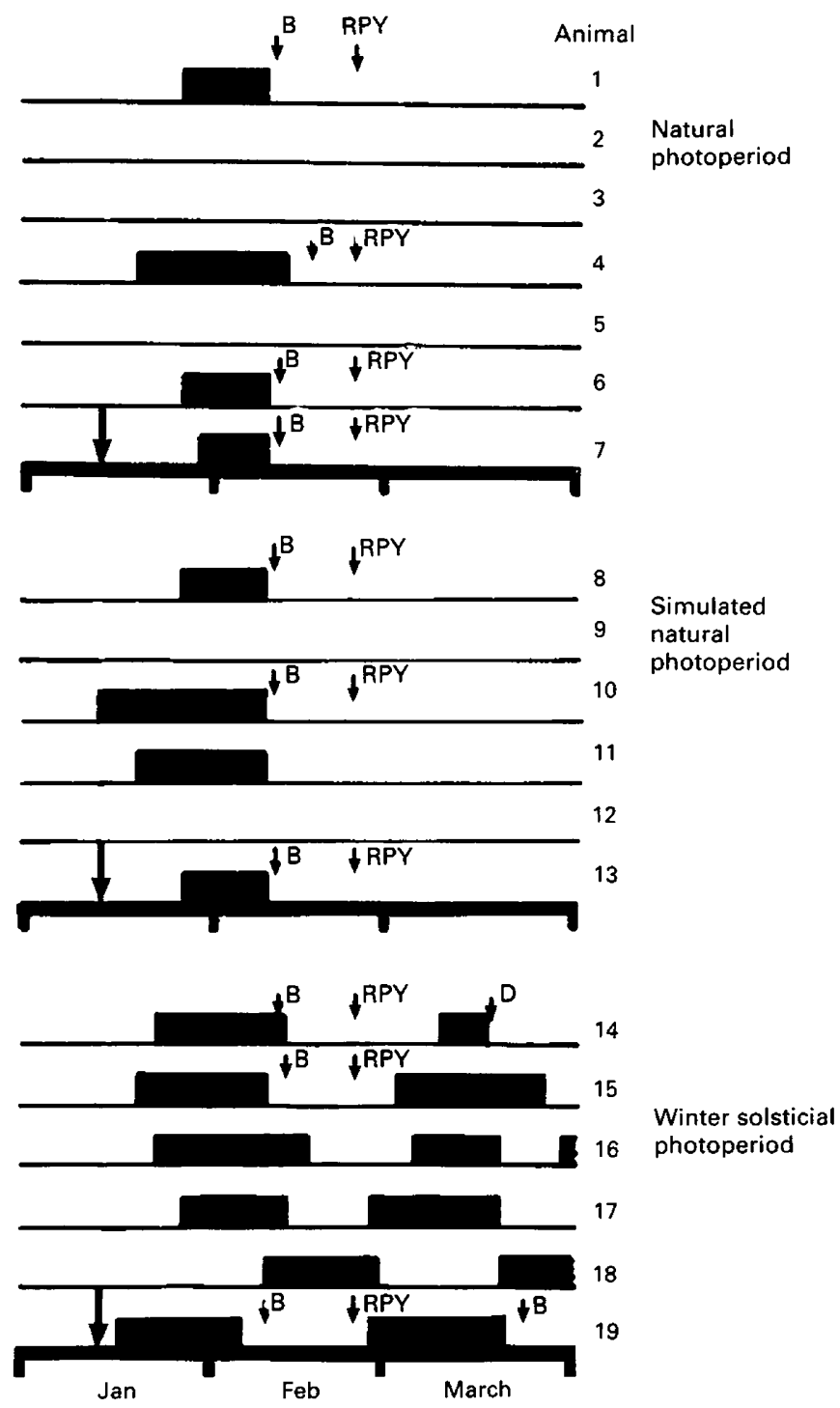

Fig. 2. Reproductive activity of female Bennett's wallabies maintained under natural photoperiodic conditions, simulated natural photoperiod or fixed winter solstitial photoperiods from 5 December. Pouch young were removed from all females on 13 January as indicated by the large vertical arrows. $B=$ births; $D=$ death of one animal (No. 14); RPY = removal of later pouch young.

cycles (Fig. 1), based on plasma progesterone concentrations in excess of $300 \mathrm{pg} / \mathrm{ml}$, beyond the time at which control animals had entered seasonal quiescence (Curlewis et al., 1987). Three animals (Nos 1, 3 and 5) had progesterone concentrations $>300 \mathrm{pg} / \mathrm{ml}$ within 12 days of removal of pouch young and 2 of these animals gave birth 28 and 30 days respectively after removal of pouch young. The remaining 3 animals (Nos 2, 4 and 6) showed evidence of a delay in reactivation of the quiescent $\mathrm{CL}$, with the first birth following removal of pouch young occurring on Days 50,63 and 54 respectively. Three animals (Nos 1, 3 and 5) showed evidence of continued reproductive cycles from February to mid-September, 2 animals (Nos 2 and 6) showed no further cycles beyond 
mid-July while one animal (No. 4) had ceased cycling by early April, $\sim 3$ weeks after the last cycle observed in 2 of the control animals. Although maintained with the same male throughout, it is clear that a number of females underwent repeated oestrous cycles without mating.

In Exp. 2 (Fig. 2), 4 of the 7 animals maintained in a natural photoperiod (Group 2a) underwent a single reproductive cycle following removal of pouch young on 13 January and in these animals birth occurred on Days 28, 29, 29 and 34 respectively. Removal of their pouch young was not followed by a reproductive cycle. In the remaining 3 animals there was no evidence of reproductive activity. Of the 6 animals maintained in a simulated natural photoperiod (Group 2b), 4 underwent a single reproductive cycle and 3 of these animals gave birth on Day 28 after removal of pouch young. Removal of these pouch young was not followed by a reproductive cycle. The 2 remaining animals showed no evidence of reproductive activity after the initial removal of pouch young. In Group 2c maintained in short days, all 6 animals showed evidence of reproductive activity after removal of pouch young and 3 animals gave birth on Days 27, 29 and 30 respectively. All 6 animals underwent a second cycle in March at a time when none of the animals in Groups 2a and $2 \mathrm{c}$ was reproductively active.

\section{Discussion}

Our results demonstrate that increasing daylengths shortly after the winter solstice are required to initiate normal seasonal quiescence and that the Bennett's wallaby does not enter reproductive quiescence due to refractoriness to short photoperiods. It is clear from our results that the relatively small increase in photoperiod after the winter solstice provides the crucial environmental cue which initiates the onset of seasonal quiescence. These experimental data accord with the earlier observation that Bennett's wallabies do not normally enter seasonal quiescence until 6-8 weeks after the winter solstice (Curlewis et al., 1987). Our data do not reveal whether wallabies enter quiescence due to a directional change in photoperiod or whether quiescence is initiated as a result of exposure to photoperiods in excess of a critical level.

The results also indicate that wallabies maintained in short daylengths may not necessarily continue to undergo reproductive cycles with a periodicity of 27-28 days for pregnant and 28-35 days for non-pregnant cycles (Merchant \& Calaby, 1981; Curlewis et al., 1987). An increased interval to birth after removal of pouch young was observed in both experiments and indicates that a short period of quiescence may have occurred before reactivation of the CL. Although the normal interval from removal of pouch young to birth is $27-28$ days in the middle of the breeding season we have previously reported that there is on occasion an increased interval of a few days in animals following removal of pouch young in late January close to the end of the breeding season (Loudon \& Curlewis 1987). Consequently, short photoperiods may prevent the establishment of a stable state of reproductive quiescence such that animals maintained in these photoperiods alternate between short periods of quiescence of variable duration followed by reactivation. Evidence in favour of this hypothesis derives from the observation that in 3 animals which had pouch young removed in June (Nos 1, 2 \& 6) and were subsequently blood-sampled daily for 14 days, there was a transient progesterone peak (indicating reactivation of the quiescent CL) 7,11 and 14 days after the removal of pouch young. In the normal breeding season this interval is 4 or 5 days (Curlewis et al., 1987).

In our experiments, the light chambers were not rigorously controlled for temperature and it is possible that environmental information may have been perceived by animals maintained for many months in fixed winter solstitial photoperiods (Exp. 1 only). This is particularly important since prolactin is implicated as the agent responsible for the maintenance of luteal quiescence in this species (Curlewis \& Loudon, 1988b; Brinklow \& Loudon, 1989) and the secretion of this hormone is known to be elevated by high environmental temperatures in cattle (Tucker \& Wettemann, 1976) and sheep (Ebling \& Lincoln, 1987). It is possible therefore that, in the absence of a long-day 
photoperiodic signal, high ambient temperatures may have stimulated prolactin release which may have blocked the reactivation of the corpus luteum for a variable length of time.

There is evidence that the transition from the breeding season to seasonal quiescence in wallabies is dependent upon a functional pineal gland and changes in the secretion of melatonin. In the tammar wallaby, superior cervical ganglionectomy performed in the middle of the breeding season prevents the normal nocturnal rise of melatonin and the transition to seasonal quiescence (Renfree et al., 1981). Ganglionectomized tammars continued to cycle following the removal of pouch young from the time of normal onset of seasonal quiescence through to the following summer solstice. In the Bennett's wallaby, animals maintained on fixed winter solstitial photoperiods from December to 27 January exhibit no significant difference in the daily duration of elevation of melatonin based on 24-h profiles measured on 4 occasions over this period (Curlewis \& Loudon, 1988a). The present results demonstrate that such photoperiodic treatments also block the onset of seasonal quiescence. Furthermore, Silastic elastomer implants containing melatonin administered towards the end of the breeding season maintain supraphysiological plasma concentrations of melatonin and also block the onset of reproductive quiescence (B. R. Brinklow \& A. S. I. Loudon, unpublished observations), presumably by preventing the animals from perceiving a reduction in the duration of the night-time melatonin rise. Photoperiodic information, conveyed via the daily pattern of melatonin secretion, is probably therefore the major factor determining the timing of the onset of seasonal quiescence.

Very short photoperiods or exogenous melatonin (implants or injections timed $2-3 \mathrm{~h}$ before dusk) administered in early seasonal quiescence are not effective in terminating quiescence (Loudon \& Curlewis, 1987). However, in mid- to late seasonal quiescence, treatment with exogenous melatonin or artificial short photoperiods are effective in terminating quiescence in both the tammar and Bennett's wallaby (tammar: Hinds \& den Ottolander, 1983; McConnell \& Tyndale-Biscoe, 1985; Bennett's wallaby: Loudon et al., 1985; Loudon \& Curlewis, 1987). The increase in photoperiod after the winter solstice may therefore have the primary effect of initiating seasonal quiescence (via a pineal-dependent process) but a long period of exposure to increasing photoperiods may be required before short photoperiods or exogenous melatonin are capable of terminating seasonal quiescence. Evidence in support of this derives from the observation that exposure to 4 weeks of long photoperiods in early quiescence restores sensitivity to the stimulatory effects of short photoperiods at a time of year when animals maintained in natural photoperiods are insensitive to such treatments (Loudon \& Curlewis, 1987).

Our results differ markedly from recent publications describing the photoperiodic control of the annual cycle of the seasonally breeding sheep. Sheep and seasonal wallabies both exhibit long-day photorefractoriness since exposure to fixed summer solstitial photoperiods from the time of the summer solstice does not block the onset of the normal breeding season in the ewe (Robinson et al., 1985) or the reactivation and growth of the testis in the ram (Almeida \& Lincoln, 1984) or the onset of the breeding season in the Bennett's wallaby (Curlewis \& Loudon, 1989). However, ewes and rams exposed to constant short days from the winter solstice cease cycling or undergo testicular regression at the same time as controls, a phenomenon frequently termed as short-day photorefractoriness (ewes: Robinson \& Karsch, 1984; rams: Lincoln, 1980). In the ewe, there is good evidence that transitions in reproductive state occur independently of the melatonin signal such that animals maintained long term in fixed summer or winter solstitial photoperiods continue to exhibit daily patterns of melatonin secretion which are appropriate to the photoperiod in which the animals are maintained (Robinson \& Karsch, 1984; Karsch et al., 1986). In this respect, sheep exhibit a loss of response both to inductive and inhibitory photoperiods. Current research on sheep has led to the concept that the role of photoperiod is to entrain endogenous rhythms of reproduction, rather than directly drive reproductive activity (Robinson et al., 1985; Robinson \& Karsch, 1988; Karsch et al., 1988). Several studies have shown that sheep exhibit long-term changes in reproductive state when maintained in fixed photoperiods (Ducker et al., 1973; Howles et al., 1982; Almeida \& Lincoln, 1984; Jackson et al., 1988) and such spontaneous changes have been taken as evidence of a 
'circannual' rhythm which is normally tuned by photoperiod (Karsch et al., 1988). Our results, based on relatively short-term experiments, would indicate that there is little evidence for wallabies for the operation of a circannual rhythm controlling reproduction of the sort reported for sheep. In the absence of a changing photoperiodic signal, the Bennett's wallaby exhibits a 'default' response and effectively becomes a continuous breeder. Differences between wallabies and seasonal eutherians may be a reflection of the different physiological mechanisms whereby seasonality is established in wallabies (via prolactin rather than the seasonal control of gonadotrophins: Tyndale-Biscoe et al., 1986, Curlewis \& Loudon, 1988b; Brinklow \& Loudon, 1989), rather than indicating fundamental differences in the way in which the photoperiod signal is interpreted by macropodid marsupials or sheep. The only seasonally breeding eutherian mammal which is reported to require photostimulation shortly after the winter solstice in order to time the onset of the breeding season is the mink. In this species, there is also an embryonic diapause and, as in the wallaby, prolactin is implicated as the hormonal control mechanism (Martinet et al., 1984).

We thank Alison White, Anne Coleman and Serena Williams for help in the blood sampling of animals and determination of hormone concentrations; Alison Beasey, Mike Llovet and staff of the Animal Hospital at the Institute for help in the capture and management of animals, and Dr B. Brinklow for criticism of an earlier draft of the manuscript.

\section{References}

Almeida, O.F.X. \& Lincoln, G.A. (1984) Reproductive photorefractoriness in rams and accompanying changes in the patterns of melatonin and prolactin secretion. Biol. Reprod. 30, 143-I 58.

Boyd, I. (1985) Effects of photoperiod and melatonin on the testis development and regression in the wild European rabbit (Oryctolagus cuniculus). Biol. Reprod. 33, 21-29.

Brinklow, B.R. \& Loudon, A.S.I. (1989) Effect of exogenous prolactin and bromocriptine on seasonal reproductive quiescence in the Bennett's wallaby (Macropus rufogriseus rufogriseus). J. Endocr. 120, 189-193.

Canguilhem, B., Vivien-Roels, B., Demeinex, B., Miro, J.L., Masson-Pevet, M. \& Pevet, P. (1986) Seasonal and endogenous variations of plasma testosterone (T), thyroxine (T4) and tri-iodothyronine (T3) in the European hamster. In Endocrine Regulations as Adaptive Mechanisms to the Environment, pp. 291 296. Eds I. Assenmacher \& J. Boisson. CNRS, Paris.

Carter, D.S., Hall, V.D., Tamarkin, L. \& Goldman, B.C. (1982) Pineal is required for testicular maintenance in the Turkish hamster (Mesocricetus brandti). Endocrinology 111, 863-871.

Curlewis, J.D. \& Loudon, A.S.I. (1988a) Effects of photoperiod on the 24-hour melatonin profiles of the Bennett's wallaby (Macropus rufogriseus rufogriseus). J. Pineal Res. 5, 373-384.

Curlewis, J.D. \& Loudon, A.S.I. (1988b) Experimental manipulations of prolactin following removal of pouch young or bromocriptine treatment during lactational quiescence in the Bennett's wallaby. $J$. Endocr. 119, 405-411.

Curlewis, J.D. \& Loudon, A.S.I. (1989) The role of refractoriness to long daylengths in the reproductive cycle of the female Bennett's wallaby (Macropus rufogriseus rufogriseus) J. exp. Zool. (In press).

Curlewis, J.D., White, A.S., Loudon, A.S.I. \& McNeilly, A.S. (1986) Effects of lactation and season on plasma prolactin concentrations and response to bromocryptine during lactation in the Bennetts wallaby (Macropus rufogriseus rufogriseus). J. Endocr. 110, 59-66.

Curlewis, J.D., White, A.S. \& Loudon, A.S.I. (1987) The onset of seasonal quiescence in the female Bennett's wallaby (Macropus rufogriseus rufogriseus). $J$. Reprod. Fert. 80, 119-124.

Ducker, M.J., Bowman, J.C. \& Temple, A. (1973) The effect of constant photoperiod on the expression of oestrus in the ewe. J. Reprod. Fert., Suppl. 19, 143-150.

Ebling, F. \& Lincoln, G.A. (1987) Beta-endorphin secretion in rams related to season and photoperiod. Endocrinology 120, 809-818.

Flint, A.P.F. \& Renfree, M.B. (1982) Oestradiol-17 $\beta$ in the blood during seasonal reactivation of the diapausing blastocyst in a wild population of tammar wallabies. Endocrinology 95, 293-300.

Hinds, L.A. \& den Ottolander, R.C. (1983) Effect of changing photoperiod on peripheral plasma prolactin and progesterone concentrations in the tammar wallaby (Macropus eugenii). J. Reprod. Fert. 69, 631-639.

Hinds, L.A. \& Tyndale-Biscoe, C.H. (1982) Plasma progesterone levels in the pregnant and non-pregnant tammar, Macropus eugenii. J. Endocr. 93, 99-107.

Hoffmann, K. (1973) The influence of photoperiod and melatonin on testis size, body weight and pelage colour in the Djungarian hamster. J. comp. Physiol. 85, 267-282.

Howles, C.M., Creighton, J. \& Haynes, N.B. (1982) Long term rhythms of testicular volume and plasma prolactin concentrations in rams reared for 3 years in constant photoperiod. J. Reprod. Fert. 65, 439-446.

Jackson, G.L., Gibson, M. \& Kuehl, D. (1988) Photoperiodic disruption of photorefractoriness in the ewe. Biol. Reprod. 38, 127-134. 
Karsch, F.J., Bittman, E.L., Robinson, J.E., Yellon, S.M., Wayne, N.L., Olster, D.H. \& Kaynard, A.H. (1986) Melatonin and photorefractoriness: Loss of response to the melatonin signal leads to seasonal reproductive transitions in the ewe. Biol. Reprod. 34, 265-274.

Karsch, F.J., Malpaux, B., Wayne, N.J. \& Robinson, J.E. (1988) Characteristics of the melatonin signal that provide the photoperiodic code for timing seasonal reproduction in the ewe. Reprod. Nutr. Develop. 28 (2B), 459-472.

Lincoln, G.A. (1980) Photoperiodic control of seasonal breeding in rams-the significance of short day refractoriness. In Proc. 6th Int. Congress Endocr., pp. 283-286. Eds I. A. Cumming, J. W. Funder \& F. A. O. Mendelsohn. Australian Academy of Sciences, Canberra.

Loudon, A.S.I. \& Curlewis, J.D. (1987) Refractoriness to melatonin and short daylengths in early seasonal quiescence in the Bennett's wallaby (Macropus rufogriseus rufogriseus). J. Reprod. Fert. 81, 543-552.

Loudon, A.S.I., Curlewis, J.D. \& English, J. (1985) The effect of melatonin on the seasonal embryonic diapause of the Bennett's wallaby (Macropus rufogriseus rufogriseus). J. Zool., Lond. 206, 35-39.

Martinet, L., Allain, D.C. \& Weiner, C. (1984) Role of prolactin in the photoperiodic control of moulting in the mink (Mustela vison). J. Endocr. 103, 9-15.

McConnell, S.J. \& Hinds, L.A. (1985) Effect of pinealectomy on plasma melatonin, prolactin and progesterone concentrations during seasonal reproductive quiescence in the tammar (Macropus eugenii). $J$. Reprod. Fert. 75, 433-440.

McConnell, S.J. \& Tyndale-Biscoe, C.H. (1985) Response in peripheral plasma melatonin to photoperiod change and the effects of exogenous melatonin on seasonal quiescence in the tammar wallaby (Macropus eugenii). J. Reprod. Fert. 73, 529-538.

McConnell, S.J., Tyndale-Biscoe, C.H. \& Hinds, L.A. (1986) Change in duration of elevated concentrations of melatonin is the major factor in photoperiod response of the tammar (Macropus eugenii). J. Reprod. Fert. 77, 623-632.

Merchant, J.C. (1979) The effect of pregnancy on the interval between one oestrus and the next in the tammar wallaby (Macropus eugenii). J. Reprod. Fert. 56, 459-463.
Merchant, J.C. \& Calaby, J.H. (1981) Reproductive biology of the Red-necked Wallaby (Macropus rufogriseus banksianus) and Bennett's wallaby ( $M$. rufogriseus rufogriseus) in captivity. J. Zool., Lond. 194, 203-217.

Nicholls, T.J., Goldsmith, A.R. \& Dawson, A. (1988) Photorefractoriness in birds and comparison with mammals. Physiol. Rev. 68, 133-176.

Renfree, M.B. (1979) Initiation of development of diapausing embryo by mammary denervation during lactation in a marsupial. Nature, Lond. 278, 549-551.

Renfree, M.B., Lincoln, D.W., Almeida, O.F.X. \& Short, R.V. (1981) Abolition of seasonal embryonic diapause in a wallaby by pineal denervation. Nature, Lond. 293, 138-139.

Robinson, J.E. \& Karsch, F.J. (1984) Refractoriness to inductive day lengths terminates the breeding season of the Suffolk ewe. Biol. Reprod. 31, 656-663.

Robinson, J.E. \& Karsch, F.J. (1988) Timing the breeding season of the ewe: what is the role of daylength? Reprod. Nutr. Dev. 28 (2B), 365-374.

Robinson, J.E., Wayne, N.L. \& Karsch, F.J. (1985) Refractoriness to inhibitory daylengths initiates the breeding season of the Suffolk ewe. Biol. Reprod. 32, $1024-1030$.

Sadleir, R.M.F.S. \& Tyndale-Biscoe, C.H. (1977) Photoperiod and the termination of embryonic diapause in the marsupial Macropus eugenii. Biol. Reprod. 16, 605-608.

Tucker, H.A. \& Wettemann, R.P. (1976) Effects of ambient temperature and relative humidity on serum prolactin and growth hormone in heifers. Proc. Soc. exp. Biol. Med. 151, 623-626.

Turek, F.W., Elliott, J.A., Alvis, J.D. \& Menaker, M. (1975) Effect of prolonged exposure to non-stimulatory photoperiod on the activity of the neuroendocrine testicular axis of golden hamsters. Biol. Reprod. 13, 475-481.

Tyndale-Biscoe, C.H., Hearn, J.P. \& Renfree, M.B. (1974) Control of reproduction in macropodid marsupials. J. Endocr. 63, 589-614.

Tyndale-Biscoe, C.H., Hinds, L.A. \& McConnell, S.J. (1986) Seasonal breeding in a marsupial: opportunities of a new species for an old problem. Recent Prog. Horm. Res. 42, 471-512.

Received 6 March 1989 